\title{
A figura feminina na literatura infanto-juvenil
}

\section{La figure féminine dans la littérature de jeunesse pour les enfants}

\section{Gilda de Castro Meirelles.}

Como citar esse artigo. Meirelles GC. A figura feminina na literatura infanto-juvenil. Revista Mosaico. 2013 Jan./Jun.; $04 \quad$ (1): 29-34.

\begin{abstract}
Resumo
A figura feminina, inserida na poética do texto, percebida em toda plenitude no tocante à posição social da mulher, no espaço, no tempo e na cultura da época. Beleza, interesse e prazer funcionando como invólucro para tornar infinito e documento histórico um segmento literário, denominado literatura infanto juvenil: onde tudo pode ser, quer nas entrelinhas quer na imagem da palavra impressa no livro, ou em outro suporte. Palavras-Chave: Literatura. Literatura Infanto-Juvenil. Folclore.
\end{abstract}

\section{Resumé}

La figure féminine, insérée dans le texte poétique, perçue diminuée en ce qui concerne à la position sociale de la femme dans l'espace, le temps et la culture de l'époque. La beauté, l'intérêt et le plaisir de travailler, comme envéloppe pour faire infini et un document historique, un segment appelé la littérature de jeunesse pour les enfants: où tout peut être soit les lignes ou l'image imprimées dans le livre, ou d'autres médias. Mots-clé: Littérature. Littérature pour les enfants et pour la jeunesse. Folklore.
Através dos tempos, o papel e o lugar da mulher estão registrados nas diferentes manifestações da arte - pintura, música, dança, poesia, teatro, literatura. E por que não, na tradicionalidade do hábito de contar histórias. Naquele transcendente brinquedo da palavra oral ou escrita que se expressa em clássicos considerados infanto-juvenis - contos de fadas, fábulas, humanizados, aventura, fantasia, vida real. Na trama, embora não tenha recebido o tratamento para que os fatos apareçam sob tal enfoque, pode-se acompanhar a realidade, traçada pelo fio condutor do imaginário e pela sutileza da postura simbólica.

Embora, especificamente, não tenham sido escritos com esta finalidade, tais textos percorreram a infinitude dos anos e chegaram até nós sob a identificação de um rótulo, isto é, voltados para uma determinada faixa etária do desenvolvimento humano. No entanto, a realidade desmente o pressuposto e projeta que, na verdade, o interesse não está limitado a qualquer certidão de idade.

Além disso, tais narrativas sofreram inúmeras interpretações, influenciadas pela criatividade dos autores e pelas características - políticas, religiosas, filosóficas, morais, culturais - da sociedade de época. Assim ao nos defrontarmos com qualquer um dos veículos históricos, podemos fazer uma leitura pelos elementos que as manifestações artísticas colocam diante de nós, na percepção da individualidade do sentir.

Mas o que vem ao caso, aqui, é a presença do gênero feminino, inserido nesses textos literários.

Analisemos o enredo de alguns, buscando o contraponto da linguagem simbólica contida nos seres humanos vestidos como personagem mulher. 


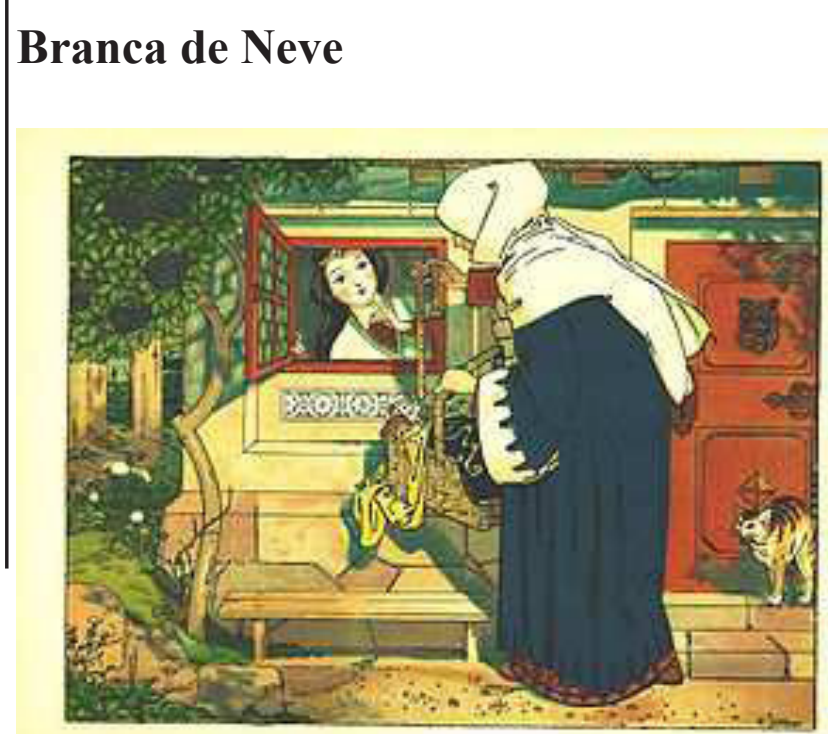

Irmãos Grimm - Branca de Neve, ilustração de 1905, feita por Franz Jüttner - Fonte: Wikipédia

- o belo e a docilidade;

- a beleza e a feiura;

- o poder e a disputa;

- o comando e a obediência;

- as personalidades;

- os sentimentos: inveja/ ódio/ amor/ orgulho;

- o espelho como reflexo de si mesma ou a projeção daquilo que se deseja ver.
A Dualidade
O Eco dos Contrários
Os Opostos

\section{Cinderela}

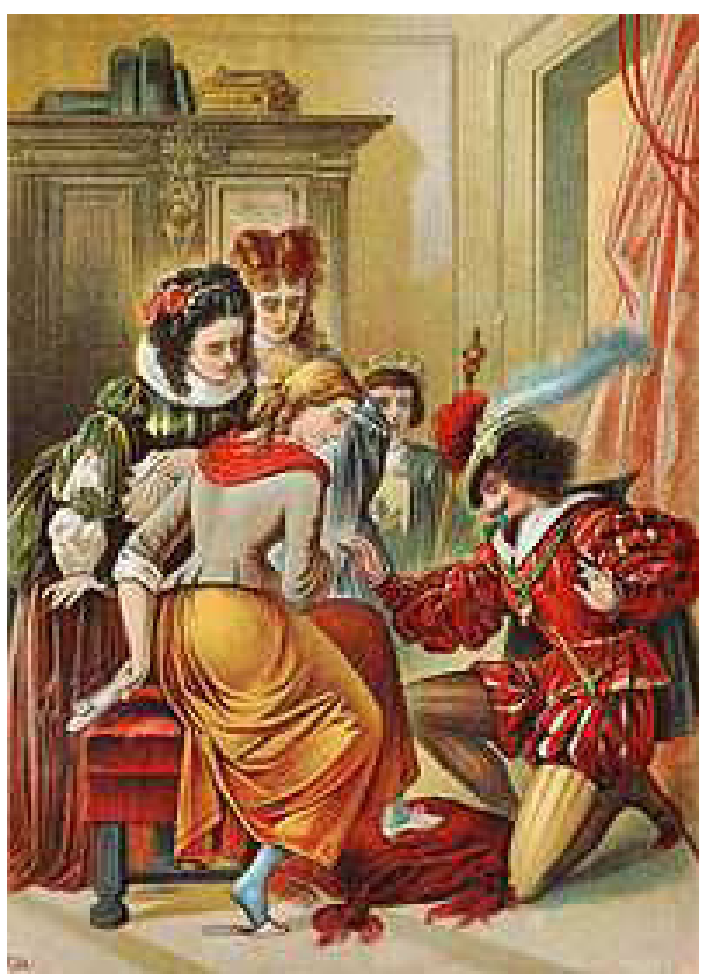

Cinderela, ilustração de Carl Offterdinger. Fonte Wikipédia
- o sonho e a fantasia;

- a transformação ("fada madrinha");

- a relação afetiva;

- a disputa e a fragilidade;

- o poder do mais forte;

- o brilho e o valor;

- o elemento figurativo ("sapatinho de cristal").

A Feminilidade

A Beleza

O Desejo

\section{Chapeuzinho Vermelho}

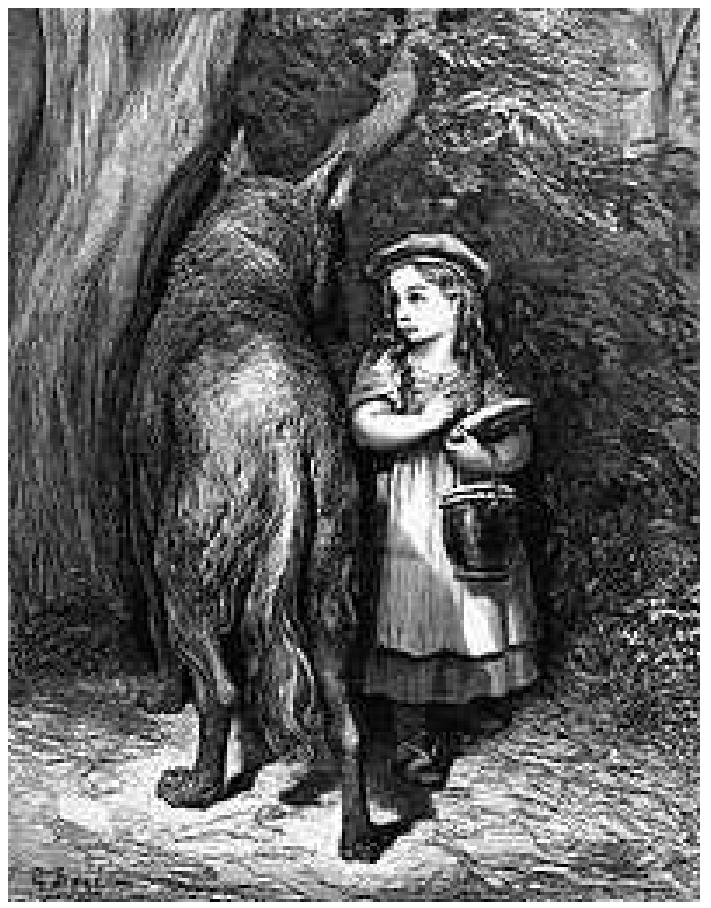

Ilustração de Gustave Doré - Fonte Wikipédia

$\underline{\text { Charles Perrault }}$

- os papéis das gerações;

- o encontro e os desencontros;

- a esperteza e a inocência;

- a verdade e a mentira;

- a obediência e a desobediência às regras;

- e a representação simbólica da cor - ("vermelho = perigo")

A Família

A Sedução

O Alimento - Corpo-Espírito 


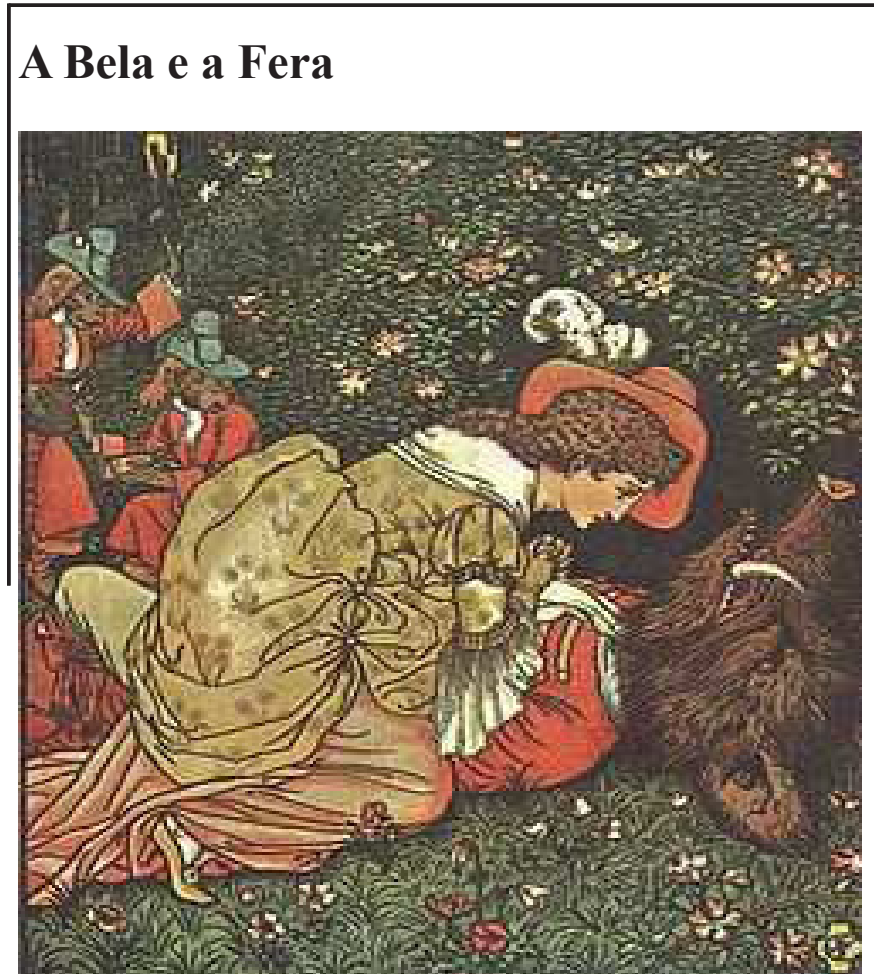

Ilustração para a edição de "Beauty and the Beast", Walter Crane, Londres: G. Routledge and Sons, 1874.

Fonte: Wikipédia

- o feio e o bonito;

- o conflito das emoções;

- as relações afetivas;

- o sagrado e o profano;

- o humano e o animal;

- o racional e o irracional;

- o diferente.

Os Valores

As Aparências

Os Preconceitos

\section{Rapunzel}

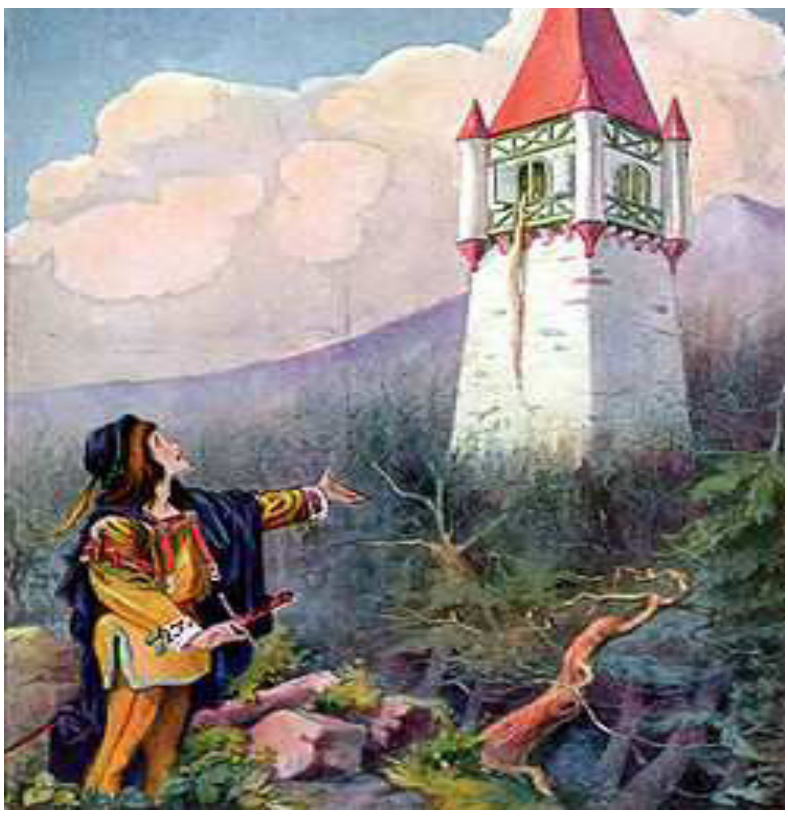

Rapunzel - Fonte Wikipédia - Irmãos Grimm
- o relacionamento: mãe/ filha;

- vencer os obstáculos;

- as estratégias;

- a reclusão e a liberdade;

- o sexo e a união permitida;

- o homem e a mulher;

- a conquista.

$O$ Permitido

A Beleza

O Sofrimento

\section{Sítio do Picapau Amarelo - Narizinho, Dona Benta, Tia Nastácia}

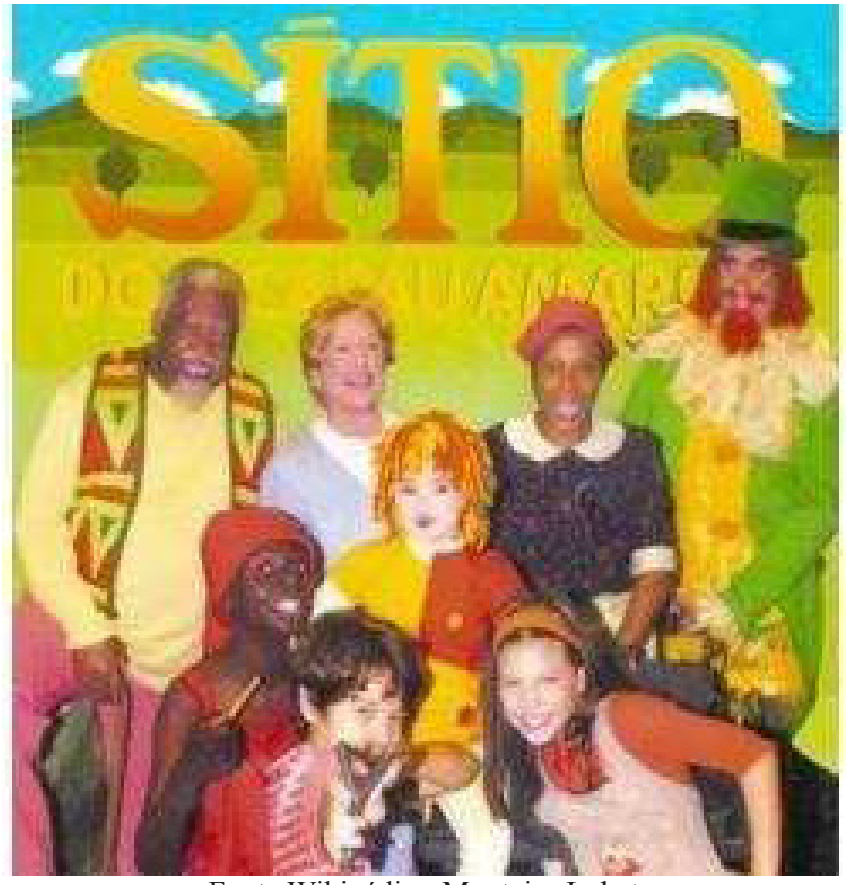

Fonte Wikipédia - Monteiro Lobato

- o quotidiano;

- as tarefas e o desempenho;

- as gerações: neta/crianças-avó/idoso;

- as funções: negra/empregada;

- a sabedoria x a experiência;

- a educação e a escola;

- o brinquedo e o folclore.

A Palavra - Ação

Contexto Social

Realidade 


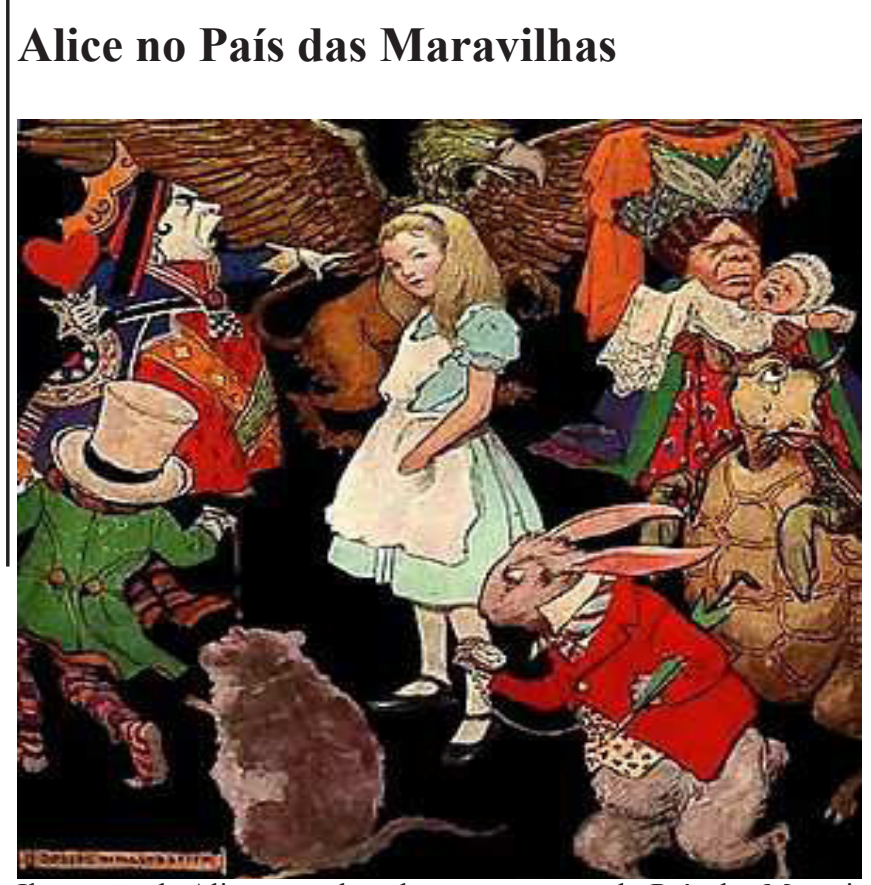

Ilustração de Alice cercada pelos personagens do País das Maravilhas, Peter Newell. (1890) Fonte Wikipedia

-o fazer e o desfazer;

$\underline{\text { Levis Carroll (Charles L.Dogson) }}$

- o fantástico e o mágico;

- as possibilidades da mudança de tamanho;

- o espelho;

- os objetos: chave/relógio/ baralho;

- as relações com o ambiente do cotidiano;

- a transformação.

Viver a Vida

Experimentar

Buscar e Arriscar

No maravilhoso e no encantamento que envolvem os contos citados, encontramos a essência do real/ imaginário e, até, do imaginário/real - o contraponto e o complemento que nos dizem muito, porque são elementos corresponsáveis para a estruturação da personalidade.

Ao se percorrer o complexo e vasto mundo da fantasia, há a vivência do brincar e contar histórias através de infinitos enredos e recursos - livros, filmes, música, peças teatrais, instrumentos da tecnologia contemporânea etc...

A presença do feminino - a mulher - aparece, ainda, nas seguintes obras:

- As amazonas (lenda)

- fábulas: A mulher e a gata - (La Fontaine)

- contos: As mil e uma noites - (M. Galland)

Ou em obras de temas idênticos ou neles inspirados, como Chapeuzinho Amarelo (Chico Buarque).
Inúmeros autores e livros de qualidade continuam a aparecer no campo editorial. Eis alguns exemplos:

"Menina Nina" (Ziraldo)

- a família;

- a afetividade;

- a morte.

“A menina das caretas" (Elza Cesar Sallouti)

- os sentimentos;

- a expressão;

- o sonho.

"Era uma vez duas avós" (Naumim Aizen)

- o desempenho de papel familiar;

- a diferença de temperamento;

- a aprendizagem da vida.

"A vida e a obra de Aletrícia depois de Zoroastro" (Bartolomeu Campos de Queirós)

- o excesso do hábito;

- as letras;

- o amor, o humor, o surpreendente.

Coelho)

"Dormir fora de casa" (Ronaldo Simões

- relação mãe e filha;

- a experiência nova;

-o deixar crescer.

"O mar de Mariana" (Rogério Borges)

- a natureza;

- o encanto;

- a criança.

Sem entrar em maiores aprofundamentos, encerramos, num resgate ao enlevo do contar histórias.

\section{Idade Média - Europa}

Literatura oral, recontada por Ruth Rocha, no livro Histórias de antigamente.

\section{Mulheres de Coragem}

Foi na Alemanha que esta história aconteceu.

Há muitos e muitos anos. A guerra já durava havia muito tempo.

As tropas do Imperador Conrado III cercavam o castelo do Rei Welfo VI. 
Antes que o cerco começasse, quando perceberam que as tropas inimigas se aproximavam, os habitantes do castelo já tinham fugido nas suas carroças, nos seus carros de boi ou mesmo a pé, carregando o que podiam.

As crianças tinham sido mandadas para longe, para a casa dos parentes.

Ficaram apenas os soldados e os cavaleiros, para a defesa do castelo; e suas mulheres, que não quiseram abandoná-los.

O cerco já durava dois longos anos.

Nos primeiros tempos, os defensores do castelo estavam otimistas, achavam que havia possibilidade de vencer o inimigo, pela luta ou pelo cansaço.

Mas com o passar do tempo a comida foi acabando, a água foi se tornando cada vez mais difícil, as doenças começavam a se espalhar.

Os feridos se arrastavam pelos aposentos desertos do castelo, sem tratamento, sem esperança.

A invasão do castelo estava próxima. E todos sabiam que quando isso acontecesse ninguém se salvaria.

Havia desânimo e tristeza.

Um dia o Imperador mandou ao rei um cavaleiro, levando uma mensagem.

Impressionado com a lealdade das mulheres, que haviam permanecido com seus maridos, Conrado oferecia a elas a salvação: poderiam sair do castelo, atravessar o acampamento de suas tropas, que não seriam maltratadas.

E poderiam, ainda, carregar consigo o que tivessem de mais precioso. Nessa noite, enquanto os homens se preparavam para a batalha, as mulheres discutiam a fuga.

Não sabemos o que se passou nessa noite.

O que sabemos é que de manhã, muito cedo, quando os raios de sol iluminaram os portões, um grupo de mulheres saiu, trazendo uma grande bandeira branca.

Dirigiu-se ao acampamento do inimigo.

Ao encontrar a primeira sentinela, uma das mulheres adiantou-se e pediu para falar com o Imperador. Conrado recebeu-as, cada vez mais impressionado com a sua valentia.

As mulheres tinham vindo perguntar ao Imperador se podiam, realmente, contar com sua palavra. Se podiam, de verdade, sair do castelo, carregando o que tinham de mais precioso.

Ofendido, ele reafirmou sua palavra:

- Palavra de rei não volta atrás! Ele deve ter dito.

As mulheres então voltaram ao castelo, para executar o plano.

Daí a pouco começaram a sair, envoltas em suas pesadas capas de viagem, caminhando com dificuldade. Pois nos ombros traziam o que tinham de mais precioso.
Ante o olhar atônito dos homens de Conrado, as mulheres passavam, com seus maridos nos ombros.

Os soldados se voltaram para o chefe, aguardando suas ordens.

Mas Conrado, impassível, mantinha sua palavra, deixando que toda a tropa inimiga passasse por entre suas próprias tropas, protegida pela coragem de suas mulheres.

Contam que o castelo não foi nem invadido.

Ali mesmo no campo de batalha, Welfo e Conrado se encontraram e a paz foi feita.

E puderam todos voltar para suas casas e esquecer, por algum tempo, que existia guerra...

\section{Referências}

AIZEM, Naumin. Rapunzel. Rio de Janeiro: Ebal, s./d.

AIZEM, Naumin. Era uma vez duas avós. Ilustrações de Patrícia Guvinner. Rio de Janeiro: EBAL, 1980.

ALBERGARIA, Lino de: Do folhetim à literatura infantil. Belo Horizonte, MG: Lê, 1996

ANJOS, Edgard S. dos e Aidelita A. Bernardez. O mundo do faz - de conta. Rio de Janeiro: Shogun, 1985.

BENJAMIN, Walter. Reflexões: A criança - o brinquedo - a educação. São Paulo: Summus, 1984.

BORGES, Rogério. O mar de Mariana. São Paulo: Scipione, 1992.

BUARQUE, Chico. Chapeuzinho Amarelo. Rio de Janeiro: Berlendis Vertecchia, 1983.

BUSATTO, Cléo. A arte de contar histórias no século XXI. Petrópolis, RJ: Vozes, 2006.

CATHERINE, Barnes. Cinderella. Rio de Janeiro: O Cruzeiro, 1965.

COELHO, Betty. Contar histórias: uma arte sem idade. São Paulo: Ática, 1986.

COELHO, Nelly Novaes. Literatura infantil. São Paulo: Quiron; Brasília: INL, 1981 .

COELHO, Ronaldo Simões. Dormir fora de casa. Ilustrações: Edna de Castro. São Paulo: FTD, 1989.

DISNEY, Walt. Branca de Neve e os sete anões: Máyora, (filme).

EBOLI, Terezinha. Branca de Neve os sete anões. Rio de Janeiro: Record, 1982.

GALLAND, M. As mil e uma noites. São Paulo: Edigraf, s/d.

GRIMM, Jacob e Wilhelm. Rapunzel. Porto Alegre, RS: Kuarup, 1985.

HELD, Jacqueline. O imaginário no poder. São Paulo: Summus, 1980.

MACHADO, Ana Maria. Chapeuzinho Vermelho. Rio de Janeiro: Nova Fronteira, 1986.

MAZZETTI, Maria. Chapeuzinho Vermelho. Rio de Janeiro: Record, 1982.

MEIRELLES, Cecília. Problemas da literatura Infantil. Rio de Janeiro: Nova Fronteira, 1984.

MUNIZ, Flávia; ilustrações de Walter Ono. Rita, não grita! São Paulo: Melhoramentos, 1985.

QUEIRÓS, Bartolomeu Campos de. A Vida e obra de Aletrícia depois de Zoroastro. São Paulo: Moderna, 2003. 
RIBEIRO, Jonas. Ouvidos dourados. São Paulo: Ave Maria, 2001.

ROCHA, Ruth. Histórias de antigamente. Ilustrações: Rogério Borges. Rio de Janeiro: José Olympio, 1986.

RODARI, Gianni. Gramática da fantasia. São Paulo: Summus, 1982.

SÁ, João Gomes de. Ilustrações: Marcos Garuti. Alice no País das Maravilhas (em cordel). São Paulo: Nova Alexandria, 2010.

SALEM, Nazira. Literatura infantil. São Paulo: Mestre Jou, 1959.

SALLDUTTI, Elza César. A menina das caretas. Ilustrações de Lila Figueiredo. São Paulo: Record, 1980.

SANDRONI, Laura. De Lobato a Bojunga. Rio de Janeiro: Agir, 1987.

"Sítio do Picapau Amarelo" DVD, Globo Marcas, 2009.

TEIXEIRA, Fábio. A Bela e a Fera. Contos de Fadas. Livro Sonoro. São Paulo: Ciranda Cultural, 2009.

YUNES, Eliana/ Glória Pondé. Leitura e leituras da literatura infantil. São Paulo: FTD, 1988.

ZIRALDO. Menina Nina. São Paulo: Melhoramentos, 2002. 